\title{
Nodular Hidradenoma
}

National Cancer Institute

\section{Source}

National Cancer Institute. Nodular Hidradenoma. NCI Thesaurus. Code C7568.

A benign epithelial neoplasm arising from the sweat glands. It presents as a nodular lesion usually in the scalp, trunk, and proximal extremities. It is characterized by a nodular growth pattern. Complete excision is curative. 